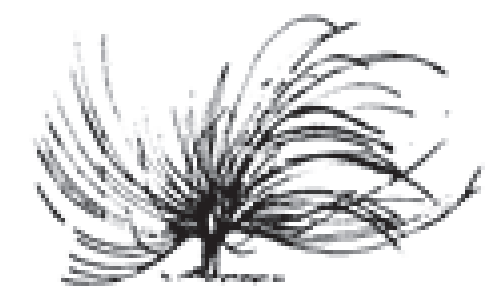

\title{
El Papel de la Transmisión Intergeneracional en el Involucramiento de los Jóvenes en la Acción Colectiva
}

\author{
Ana Corina Fernández Alatorre ${ }^{1}$ \\ Universidad Pedagógica Nacional \\ México, D.F., México \\ corinaf@prodigy.net.mx
}

\begin{abstract}
Resumen
En este trabajo se muestran algunos de los resultados de un estudio realizado en México desde 2011, con el fin de aproximarse a los procesos de construcción de identidad de jóvenes que, voluntariamente, se constituyen como miembros de una nueva generación de la acción colectiva (Melucci, 2002). Estos jóvenes han creado organizaciones para el desarrollo de intervenciones educativas como una vía para reconstruir contextos habituales de confianza y de sentido (Lechner, 1998), para jóvenes de comunidades marginadas, mediante el trabajo de fortalecimiento de la organización y participación colectiva. La estrategia metodológica ha incluido historias de vida,
\end{abstract}

Recibido: 9 de junio de 2014-Aprobado: 25 de octubre de 2014

1 Psicóloga Social y Doctora en Pedagogía. Profesora / investigadora de tiempo completo en la Universidad Pedagógica Nacional de México. Área académica: TEORÍA PEDAGÓGICA Y FORMACIÓN DOCENTE. Ha colaborado en libros y en revistas especializadas con artículos sobre educación ciudadana y educación para la democracia. Es autora de: Formación ciudadana e identidad: Voces de la Sociedad Civil, Entre la nostalgia y el desaliento. La Educación Cívica desde la perspectiva docente y coautora de Jóvenes y ciudadanía: disposiciones para la democracia y Una enseñanza de democracia: la Consulta Infantil y Juvenil 2000. 
grupos de discusión y observación participante, con el fin de explorar los componentes más significativos de la vida de estos jóvenes, fundadores de la organización no gubernamental, Acciones para el Desarrollo Comunitario, A.C. Dado que esta es la continuación de un estudio previo, (Fernández, 2010), que se aproximó a los procesos identitarios de actores sociales de la década de 1980, se explora, para esta nueva investigación la posibilidad de encontrar rasgos similares a sus predecesores. Los principales resultados refieren al papel jugado por el soporte familiar inicial, las experiencias formativas formales y no formales, y la transmisión intergeneracional, en el involucramiento de estos jóvenes en el fortalecimiento de la organización y la participación colectiva.

Palabras clave: jóvenes, participación comunitaria, formación ciudadana, ciudadanía

\begin{abstract}
This paper displays some findings of an ongoing qualitative study conducted in Mexico since 2011 in order to approach the process of establishing the identity of young adults who voluntarily, became members of a new collective action generation (Melucci, 2002). These youngsters created organizations for the development of communitarian educational interventions as a means to rebuild everyday contexts of trust and meaning, Lechner (1998) for outcast youngsters through collective participation and organization empowerment. The methodological strategy used included life stories, focus groups, and participant observation in order to explore the meaningful life's components of youth organization founders of "Acciones para el Desarrollo Comunitario, A.C.," a non-governmental organization. Since this is a continuation of a previous research Fernández (2010), which explored identity processes of social actors of the 80 s in Mexico, we examine in this new research the possibility that this new generation of social actors present similar features to those of their predecessors. The main findings here are linked to the role of family's initial support, the formative, formal and not formal experiences, and the intergenerational transmission
\end{abstract}


in the involvement of these young adults in collective participation and organization strengthening.

Keywords: youngsters, social activism, education, citizenship

\section{Introducción}

$\mathrm{D}$ esde hace ya varias décadas se perfila la necesidad de asumir la existencia de nuevos espacios de identificación entre los jóvenes, que dan lugar a nuevas formas de pertenencia y significados sociales (Castro y Rodríguez, 2012). Por ello, es preciso desplazar los estudios sobre la educación ciudadana, más allá del espacio escolar en un reconocimiento de las transformaciones sufridas, por las instituciones y la emergencia de nuevos actores políticos, que impulsan formas de participación sustantiva (Torres, 2001), es decir, aquella que apunta, no sólo al señalamiento de los síntomas de las problemáticas sociales, sino a aquella que se ocupa desde el análisis de sus causas hasta el involucramiento en el desarrollo de propuestas que permitan abatir los efectos de la exclusión de grandes sectores de la población.

Durante un período considerable, la mayoría de los trabajos sobre ciudadanía en América Latina, se han ocupado de dar cuenta de las carencias y debilidades en el ejercicio de la ciudadanía, inscribiéndose en un marco normativo y soslayando la visibilidad de todas aquellas prácticas, que van más allá de la medición de la participación ciudadana, en función de su legalidad o su ilegalidad (Acevedo y Caballero, 2012), para poder explorar las condiciones de posibilidad de la construcción de una ciudadanía más activa y crítica. Estudios recientes en México, entre ellos, Fernández (2010), Acevedo, Caballero (2012), Castro y Rodríguez (2012), dan cuenta de estas formas emergentes de ciudadanía.

Esta investigación se inscribe así, con la intención de reconocer la existencia de prácticas que, aunque no se encarnen en objetos percibidos por los actores como portadores de ciudadanía, constituyen, sin embargo, claros ejemplos de formación ciudadana (Acevedo y $\mathrm{Ca}$ ballero, 2012).

Tal es el caso de las y los jóvenes, que se involucran y se comprometen en prácticas de acción social, mediante la fundación de organizaciones que desarrollan proyectos de intervención educativa 
comunitaria, dirigido a jóvenes habitantes de poblaciones marginadas, para que estos se habiliten en procesos autogestivos que les permitan hacer frente, de manera participativa, a los problemas colectivos que enfrentan en sus comunidades.

El propósito de este trabajo es el de compartir algunos de los resultados de una investigación que se preguntó por el proceso identitario de los fundadores integrantes de la organización civil Acciones para el Desarrollo Comunitario, A.C. En esta investigación, los criterios para elegir esta organización civil fueron: el hecho de que esta organización fue fundada por iniciativa de sus integrantes para promover, sin fines de lucro, procesos de desarrollo social, es decir, que se distingue de otro tipo de organizaciones que hacen trabajo asistencial o son promovidas desde los partidos políticos y alude a la metodología y al estilo de trabajo caracterizado por prácticas congruentes con los rasgos de la ciudadanía participativa.

En un primer apartado de este trabajo, se exponen los principales referentes conceptuales y metodológicos que orientaron el estudio, para después destacar el peso de las experiencias y referencias ofrecidas por la familia, así como las experiencias formativas que marcaron la forma en que estos jóvenes se involucraran en la acción social.

En el análisis de resultados se comparte una reflexión con respecto a las continuidades y discontinuidades que esta nueva generación de actores sociales presenta, respecto a los procesos identitarios de jóvenes integrantes de otra organización similar, que fue fundada casi 20 años antes. ${ }^{2}$

\section{Referencias metodológicas y conceptuales}

Las preguntas de indagación aluden a procesos identitarios. Por ello, se asume aquí una noción de identidad que va mucho más allá de

2 Los informantes que colaboraron en el primer estudio, pertenecieron como fundadores a una organización de la sociedad civil fundada en 1991 y sus historias de vida fueron recogidas y analizadas entre 2006 y 2008. Los informantes que colaboraron en este segundo estudio fundaron su organización en 2007 y fueron estudiados en 2011. Las edades de los informantes correspondientes al primer estudio, fluctúan hoy entre 45 y 65 años, mientras que las edades de los informantes del segundo estudio están entre 20 y 30 años. Las reflexiones comparativas se hacen a la luz de los hallazgos de este segundo estudio. Será demasiado delicado de mi parte, pero decir que estas personas "fueron estudiadas" me parece chocante en un trabajo con este enfoque teórico. 
rasgos de posiciones o estados de pertenencia para reconocer que la identidad es el resultado de interacciones sociales y de reconocimiento recíproco, que da lugar a procesos de construcción y reconstrucción continuos, (Aceves, 2001). De ahí se deriva una opción metodológica al reconocer, junto con Bruner (1994), que si poseemos identidad es porque podemos contar historias sobre nosotros mismos, y nuestra noción de 'yo' es una creación de nuestros relatos que devienen en autocomprensión para determinar lo que somos y lo que hemos llegado a ser.

Con base en esta consideración, el estudió se desarrolló, fundamentalmente, a partir de la recuperación de historias de vida de las y los jóvenes involucrados en la acción social. Claro está que antes fue preciso realizar una revisión bibliográfica y documental que diera sentido y horizonte a la construcción dialógica de los relatos de vida que después se fueron complementando con observación participante y grupos de discusión. De esta forma y, en concordancia con la perspectiva metodológica sostenida por (House y Howe, 1999 y Mason y Delandshere, 2010), para realizar investigación en el campo de la formación ciudadana, se abrió la posibilidad de un involucramiento más activo por parte de los sujetos informantes, quienes contaron así con la oportunidad de cuestionar, reflexionar, dialogar y deliberar en torno a nociones como país, política y ciudadanía.

La perspectiva sobre la ciudadanía desde la cual aquí se trabaja es la más cercana al republicanismo (Pettit, 1999), que, sin negar el valor de la autonomía del individuo, sostiene el reconocimiento de una noción de bien común que se construye, no a partir de principios de bien, preestablecidos por la tradición o las creencias, sino en el curso de la deliberación que se despliega a partir de la voluntad común de constituir una comunidad política. Desde la mirada de los llamados teóricos de la sociedad civil (Klymka y Wayne, 1994) esta ciudadanía participativa, deliberativa, no implica la renuncia al pluralismo de concepciones de vida como uno de los haberes irrenunciables de la sociedad civil desde sus orígenes (Cortina, 1993).

Dado que este trabajo refiere a los jóvenes, es preciso señalar el reconocimiento de esta noción como un significado que no se restringe a la edad, pues en tanto categoría histórica y construcción cultural está sometido a permanentes recomposiciones derivadas de las tensiones y dinámicas de cada sociedad. En ellas confluyen factores políticos, factores culturales y, desde luego, factores económicos como los flujos 
mercantiles que configuran determinados sujetos consumidores. Como sea, para efectos del encuadre conceptual de este trabajo, con el vocablo juventud, se hace alusión a las muy diversas formas en que cada cultura se plantea los procesos de pasaje de la infancia a la adultez. "Entendemos por juventud, una categoría histórica, una construcción cultural que alude a la forma en que cada sociedad organiza la transición de los sujetos, de la infancia a la edad adulta" (Anzaldúa, 2006, p. 107).

\section{La organización civil fundada por los informantes}

El material obtenido mediante la técnica de grupos de discusión y cinco relatos de vida, fueron recuperados mediante entrevistas a integrantes fundadores y fundadoras de una organización de la sociedad civil que, desde 2005 y sin fines de lucro, trabajan simultáneamente en varios proyectos comunitarios y se plantean como misión:

Fortalecer la organización y participación colectiva de comunidades de nuestro país, a través de diversos procesos educativos que desarrollen las capacidades y herramientas necesarias para enfrentar de manera autónoma e integral los problemas que afrontan, mejorando así su calidad de vida (ADECO, 2011).

$\mathrm{El}$ antecedente para la conformación de esta organización llamada Acciones para el Desarrollo Comunitario, Asociación Civil (ADECO) fue que desde el año 2000 el grupo fundador ha impulsado, entre jóvenes de educación media superior, campañas de alfabetización y de educación de adultos en comunidades rurales. Al respecto en su página de internet señalan: "Pensamos en los jóvenes como un grupo con enorme potencial de transformación a corto plazo y, si logramos consolidar una visión crítica y autogestiva, este potencial permanecerá al largo plazo" (ADECO, 2011). Fue a partir de lo aprendido a lo largo de las muchas experiencias del trabajo de alfabetización en zonas rurales que esta organización se planteó en 2007, el desarrollo del proyecto denominado Tlalana ${ }^{3}$ : Jóvenes y Autogestión, que se propone impulsar grupos capaces de realizar proyectos locales, participativos, viables y autosustentables que, con una visión propia y desde adentro, mejoren las condiciones de

3 Tlalana significa echar raíces, en náhuatl. 
vida del entorno y promuevan actividades que generen espacios de encuentro, recreativos, de expresión, para, desde ahí, relacionarse con la comunidad e involucrarse en su desarrollo. Declaran en la página de la organización: los grupos de jóvenes definen los temas de sus proyectos de acuerdo con sus intereses y a su visión de la comunidad (ADECO, 2011).

En sus diversos espacios de intervención, las y los informantes se plantearon el propósito de que las comunidades puedan seguir trabajando de manera autónoma después de finalizado el proyecto de intervención educativa. Para ello, buscan promover el aprendizaje y el crecimiento personal, tanto de los asociados como de los beneficiados mediante formas de trabajo que aseguren: el respeto a los derechos humanos, al medio ambiente, así como a la cultura de las comunidades, al interior de procesos de diálogo y deliberación para la toma de decisiones respecto a asuntos de interés colectivo.

\section{¿Quiénes son estos jóvenes?}

Al explorar las condiciones de producción de las prácticas y aspiraciones de estos jóvenes, hace falta una mínima referencia a elementos de la estructura social, así como del lugar que los sujetos ocupan en ella, (Bourdieu, 1998, p. 151), pues si bien la pertenencia a una determinada clase no impone un destino, si puede balizar la vía que ha de adoptar el rumbo de una vida.

En todos los relatos de vida de las y los informantes, hay evidencias de que contaron con lo que Nagel (2004) llama el sustento básico para el desarrollo de una autonomía que les permitiera pensar y pensarse para, desde ahí, imaginar y desarrollar proyectos. De esta forma, pudieron sortear los muchos obstáculos socioestructurales que, en países como México, son efecto de profundos abismos de desigualdad económica.

Estos jóvenes, hombres y mujeres, actores de la sociedad civil no son excluidos, ni viven al día; no enfrentan la precariedad de quienes habitan un puro presente; no necesitan, para anclar su identidad, de ser parte de comunidades emocionales intensas, ni echar mano de las manifestaciones contraculturales propias del neotribalismo, (Maffesolli, 1990). Tampoco sufren los efectos de la pérdida de sentido que Castoriadis (1997) señala como avance de una insignificancia que se 
expresa en el conformismo generalizado con la consecuente ausencia de pensamiento crítico y de desmovilización política.

Si bien, todos pueden ser situados como integrantes de la llamada clase media y tienen acceso a la educación superior, tampoco encajan en la categoría de jóvenes “incorporados” (Reguillo, 2000, p. 24), rendidos ante la seducción mediática para el consumo; ni tienen aspiraciones de formar parte de una cultura empresarial de "excelencia" para poder afirmarse como individuos "valiosos" (Anzaldúa, 2006, p. 17). Si en alguna clasificación hubiera que inscribirlos a fin de intentar situarlos en un mapa cultural, podría ser en la de los llamados por Reguillo (2000: 24): “alternativos".

Ya desde hace tiempo, Melucci (2002) señaló que la acción social es sostenida, en parte, por aquellos que ocupan una posición marginal o periférica respecto del mercado de trabajo. Se trata de actores relativamente jóvenes, con niveles altos de educación y entre ellos, añade, algunos son prósperos.

Las y los fundadores de esta organización no son prósperos, tampoco cuentan con ingresos regulares por la vía de empleos formales más o menos estables. De hecho, esa situación constituye una de sus mayores preocupaciones que se ponen de manifiesto en afirmaciones como: "Me preocupa mi país y no poder encontrar un trabajo que disfrute y me permita vivir" (Participante Grupo de discusión 1).

Pese a ello, no formularon, ni en sus relatos de vida, ni en las entrevistas colectivas, ningún tipo de aspiraciones vinculadas al consumo de bienes materiales, más bien figura su deseo de llegar a ser protagonistas de procesos de cambio:

"Algún día yo haré una contribución importante para cambiar este mundo" (Entrevista informante 5)

"Me gustaría que nosotros pudiéramos tener un proceso articulado en el que transformemos la realidad". (Entrevista informante 5).

En los relatos de vida recuperados se encontraron claras referencias a un tipo de familia no nuclear en el que transcurren sus infancias. Con excepción de una historia, en todas las demás se encontró que estos jóvenes son hijos de padres divorciados y, pese a ello, todos, sin excepción, contaron con redes de contención, cuidado y acompañamiento que 
hicieron posible una escucha atenta cuando así lo requirieron. Crecieron al abrigo de una mirada adulta por parte de ambos padres que, en virtud de su propia inserción en la acción social y en los nuevos movimientos sociales, pudo reconocer, a niñas, niños y a adolescentes como sujetos de derecho que pueden opinar respecto a los asuntos que les competen. Durante su infancia y adolescencia, estos jóvenes fueron objeto de cuidado y escucha y con ello pudieron ser depositarios de un horizonte ético en virtud de algunos dispositivos de formación. Todos hicieron referencia al involucramiento de sus padres en algún tipo de acción social mediante su participación en organizaciones de la sociedad civil, en trabajo para el desarrollo de comunidades rurales en extrema pobreza o mediante su participación política en actos o movimientos de oposición a violaciones de derechos políticos y sociales. Algunos incluso refieren con gusto algunas vivencias compartidas con sus padres en el marco de algunas formas de acción social como el apoyo al desarrollo de comunidades campesinas o la participación en movimientos de protesta. Los relatos de vida dan cuenta de climas familiares de respeto y confianza para plantear de manera dialógica las dificultades que fueron enfrentando en su desarrollo psicosocial y académico.

\section{La escuela, la adolescencia: procesos formativos}

Ser integrante de una familia no nuclear conformada por progenitores involucrados en la acción social, no es garantía alguna de ciudadanía crítica, responsable y participativa. Hace falta explorar más en los procesos identificatorios para cerrar el lente en aquellas experiencias que pueden jugar un papel más decisivo en la construcción de la eticidad ${ }^{4}$ (Yuren, 2011) de estos actores sociales.

Sin excepción en todos los relatos, las y los informantes hicieron referencia a dos experiencias que marcaron su identidad. Llama la atención el tono de epifanía con que la mayoría de ellos dieron testimonio de las dos experiencias formativas que se destacan como cruciales en su proceso identificatorio: Su paso por las llamadas escuelas alternativas o escuelas activas y su participación en las campañas de alfabetización en comunidades rurales.

4 Este término alude a las ideas de la vida buena de una comunidad existente en un tiempo y un espacio determinados. 
El inicio de la vida escolar de los entrevistados transcurre, para casi todos, en instituciones consideradas por ellos como tradicionales o conservadoras, pero cuando enfrentaron algún tipo de malestar frente a prácticas autoritarias, pudieron pronunciarse al respecto y contar con el apoyo para cambiar a escuelas con perspectivas más cercanas a las pedagogías críticas.

Son muchas las referencias a los buenos recuerdos de su vida escolar en estos centros. Entre ellos cabe destacar el frecuente uso de términos como feliz, felicidad y libertad. "Era mucha presión académica, pero mucha libertad, mucha responsabilidad" (Entrevista a informante 1).

"Al llegar a la nueva escuela me volvió la vida y fui tremendamente feliz". (Entrevista informante 6).

Entre las estrategias didácticas que fueron practicadas por las y los maestros de estos jóvenes hay algunas que destacan por el gusto con que son narradas y son aquellas que evocan tradiciones de la llamada Escuela Nueva surgida a finales del siglo XIX. De manera particular hacen referencia a las técnicas de Célestine Freinet (1976), tal y como lo señaló este informante: "Me encantaba la cooperativa, escribir mi libro de vida; que no me dejaban tarea; la imprenta, y sobre todo, la asamblea de la que alguna vez fui presidente" (Entrevista a informante 1).

Testimonios como los anteriores permiten dar cuenta del papel jugado por instituciones educativas que se sustentan en los principios de la pedagogía crítica y sostienen un alto nivel de exigencia académica en un marco de inclusión, tolerancia, libertad y responsabilidad que parecen haber creado un clima propicio para el desarrollo de una autonomía que puede gestionar sin violencia la diferencia y promover una relación con el conocimiento más centrada en la indagación y la reflexión que en la acumulación de información. Son todas estas condiciones clave para la formación del pensamiento crítico y las capacidades deliberativas, dos de los muchos desafíos que hoy enfrenta la escuela para constituirse como formadora de integrantes de una ciudadanía activa.

Desde niños, aprendimos a cuestionar a nuestras figuras de autoridad, a dialogar en asambleas y a cambiar las estructuras cuando éstas no funcionaban; aprendimos a escuchar, a recibir críticas y a trabajar en equipo. Cuando se crece, se conoce y se aprende a mirar el mundo de esa manera, y lo afirmó por experiencia propia, las estructuras verticales y la falta de diálogo con 
una autoridad que se percibe como abusiva, es motivo de un profundo disgusto. (Entrevista a informante 5).

La segunda experiencia compartida y muy relevante para el involucramiento en la acción social de estos jóvenes, fue su participación voluntaria, en plena adolescencia, en las campañas de alfabetización en zonas rurales. "La campaña es como otro momento que marcó mi vida. Mucho de lo que soy ahora y las cosas en las que creo, empezaron ahí" (Entrevista a informante 5).

Diversas campañas de alfabetización, inspiradas en los aportes pedagógicos de Paulo Freire y emprendidas durante los años 80 en países centroamericanos, demostraron la eficacia de sus prácticas reflexivas para promover, al interior de comunidades marginadas, formas de acción colectiva sostenidas en la autonomía de análisis para la comprensión de la realidad y su transformación.

En 1982, el hoy extinto Centro Activo Freire de la ciudad de México, convocó a sus estudiantes para que, de manera voluntaria, se involucraran en las primeras campañas de alfabetización en zonas rurales. Además del propósito de alfabetizar adultos, esta campaña se planteó, desde su inicio, la tarea de constituirse en parte sustancial de un proyecto formativo que logró involucrar a varias escuelas de corte activo en las siguientes décadas (Palmas, 2012).

Al narrar su vida, todos los entrevistados, asignan a esta primera experiencia alfabetizadora un lugar especial que, al parecer, balizó sus procesos de pasaje entre la infancia y la vida adulta. "Fue un aspecto detonante en mi vida," señala de manera textual el primer informante al narrar su historia.

Esta experiencia se constituyó en un espacio inaugural de convivencia que puso a estos adolescentes en condición de: hacerse cargo de sí mismos; organizarse y trabajar junto y para otros; ser parte de la construcción de normas de convivencia que garantizan la continuidad de la intervención educativa en la comunidad.

Hoy estos jóvenes tienen ya en su haber colectivo, los saberes acumulados gracias al recorrido de 55 comunidades de ocho estados a lo largo de los 16 años por el que han pasado poco más de 400 alfabetizadores que han sido parte del esfuerzo por acercarse a la realidad de las comunidades rurales de nuestro país. 
De haber marcado a todos los alfabetizadores por igual, habría cientos de jóvenes involucrados profundamente en la acción social, pero no es así. No todos los adolescentes alfabetizadores devinieron en actores sociales. Lo que las entrevistas nos indican es que los entrevistados contaron, además, con algunas precondiciones culturales (Brezinka, 1999: 11-16) y particulares procesos de subjetivación que favorecieron su empatía y su compromiso con los excluidos.

El ver, escuchar, tan de cerca, la vida de la gente (...) Los efectos de la migración en las familias, el dolor de la gente te agobia, te puede hacer sentir impotencia, te abre los ojos. Aunque sabes que no vas a cambiar las cosas, ahí se va dando algún tipo de construcción. (Entrevista a informante 3)

\section{Discusión de resultados}

Frente a los testimonios de estos jóvenes, se sugiere una línea de lectura, sujeta a mayor exploración, que hace pensar en la experiencia alfabetizadora como un momento donde es activado un circuito simbólico transgeneracional, vivido de otras formas por sus padres y, en un par de casos, incluso por sus abuelos, también integrantes de organizaciones civiles o movimientos sociales promotoras de desarrollo social y defensores de los derechos humanos.

Ello invita tanto al reconocimiento de algunas continuidades como al de las diferencias en los trayectos formativos entre la generación de fundadores de organizaciones civiles de la década de 1980 y los de la actual generación.

Para esta investigación se tomó como referencia una previa que estudia el caso de una organización civil promotora de desarrollo social llamada Hacia una cultura Democrática que trabaja por la defensa de los derechos de la infancia desde la década de los años 80, mediante proyectos de intervención educativa para promover ciudadanía activa en comunidades de escasos recursos (Fernández, 2010).

Ambas generaciones de actores sociales comparten historias de vida que develan una distancia crítica y una reflexividad como parte de su experiencia vital. Comparten también el hecho de que no son militantes, no pertenecen a partidos políticos, ni a movimientos sociales de forma continua. La totalidad del grupo de informantes se declara 
abiertamente laico y reconoce la necesidad de la igualdad de género, de la pluralidad y de la tolerancia. En ambos es claro su compromiso por abatir los efectos de la desigualdad de manera voluntaria, sin interés de lucro y establecen un claro deslinde respecto a las esferas del poder gubernamental. En los dos casos utilizan la intervención educativa para promover prácticas autogestivas y democratizadoras congruentes con estilos de trabajo deliberativos y autocríticos. La diferencia fundamental entre estas dos generaciones está en que a lo largo de sus procesos identificatorios, la actual generación no tuvo que vivir, como la generación de los años 80, la confrontación con los mandatos y proyectos paternos.

Los relatos de vida de los actores sociales de la década de 1980 hacen referencia a contextos familiares nucleares más o menos estables, con claras diferencias entre los roles asumidos por sus padres y sus madres. En todos los casos, las madres sólo se ocupaban de las tareas del hogar y carecían de estudios superiores. Los informantes de la década de 1980 (en su mayoría mujeres) fueron objeto de una explícita educación religiosa y asistieron a escuelas confesionales, dado que sus madres practicaban con profunda convicción los rituales de la religión cristiana. En algún momento de sus vidas, estas informantes enfrentaron momentos de ruptura y de búsqueda de sí que implicaron el paso por períodos liminares ${ }^{5}$ (Turner, 1988), una vez que se negaron a ser lo que se esperaba de ellas como mujeres. Se opusieron así al autoritarismo y a la falta de equidad en las relaciones de género para, finalmente, desembocar en procesos de constitución de una forma identitaria de relación para sí (Dubar, 2002).

Las y los informantes que colaboraron en la actual investigación sostienen también esta forma identitaria que resulta de una conciencia reflexiva y es propicia para el desarrollo de la capacidad de relación y descubrimiento de los otros, así como de procesos de gestión de la cooperación y el conflicto en virtud de la cual el sujeto se compromete activamente en:

[...] un proyecto que tiene sentido subjetivo y que implica la identificación con una asociación de pares que comparten el mismo proyecto. A este Nosotros compuesto de allegados y

5 Víctor Turner (1988) usa el término liminar para referirse a los ritos de paso en que se sitúan los sujetos transicionales que pasan por períodos de desafiliación de un orden heredado para afiliarse después a otro. 
semejantes corresponde una forma específica de Yo que se puede llamar Sí-mismo reflexivo. Es la cara del Yo que cada uno desea que reconozcan los Otros "significativos" que pertenecen a su comunidad de proyecto. (Dubar, 2002, p. 67)

En los relatos de la nueva generación de actores sociales no hay referencias a períodos críticos de desafiliación de un orden heredado para después adscribirse a otro, porque, al parecer, no fue necesario.

Los testimonios de los nuevos actores sociales aluden, aún sin que ellos así lo expliciten, a dos líneas de prácticas que les fueron transmitidas a través del ethos institucional tanto de las escuelas activas como de las campañas alfabetizadoras: el propósito de educar para la libertad sostenido por las pedagogías críticas y las prácticas de la educación popular. Ambas remiten a momentos del trayecto recorrido por un corpus de resguardo que operó para estos jóvenes como canal de transmisión para acceder a focos de sentido que de algún modo sostienen el hilo de su identidad (Debray, 1997, pp. 21-23).

No fue difícil seguir el rastro del trabajo realizado por maestros refugiados españoles y sus descendientes que, en México, pusieron en marcha proyectos educativos inspirados en tradiciones pedagógicas y posturas ético-políticas congruentes con los mejores ideales de la llamada II República Española. ${ }^{6}$ Tal es el caso de escuelas que, en su nombre asumen la huella de maestros e instituciones como Bartolomé Cossío, Herminio Almendros y el Instituto Escuela, en explícita alusión al Instituto Escuela creado en España en 1918. ${ }^{7}$

Tan sólo para ilustrar algunos rasgos característicos de su enfoque pedagógico, se destaca entre las prácticas educativas del Instituto Escuela: el prescindir de los libros de texto, las presiones y las amenazas, en un clima de respeto y solidaridad, que no les impidiera desenvolverse con soltura. Hoy, en México existen diversas instituciones que recogen

6 Fue suficiente con la mención del nombre de algunos de sus maestros o de los directores de sus escuelas para rastrear la cadena generacional pedagógica, en particular, en los casos en los que los informantes pudieron recordar que los directores o maestros eran refugiados o hijos de refugiados españoles que habían recibido alguna influencia de las experiencias de las pedagogías críticas puestas en operación durante los años de la II República Española.

7 El Instituto-Escuela fue un proyecto educativo impulsado desde 1918 y hasta la caída del gobierno republicano en 1939, a través del cual se pretendió reformar la primera y segunda enseñanza, incorporando procedimientos pedagógicos innovadores, que hacían énfasis en la participación activa del alumno. 
ese tipo de tradiciones. Tal es el caso del Instituto Escuela de México, que en su página Web declara:

Somos miembros de una sociedad civil integrada por un grupo de profesores de diversas disciplinas que ha dado estructura a un ideal en el cual la libertad, el respeto, el razonamiento y la cooperación forman parte de los aprendizajes cotidianos.

A estos cuerpos docentes, depositarios de creencias, valores y destrezas pedagógicas, se sumaron hacia la década de 1980, los memorantes de otro linaje colectivo de recreación (Debray, 1997, p. 26) que se nutre de las exigencias éticas y las experiencias educativas desplegadas en varios países de América Latina como efecto de la acción social de la Teología de la Liberación, y de las prácticas de la llamada Educación Popular, desarrollada por Paulo Freire y enriquecida por importantes aportes de psicólogos sociales profundamente comprometidos con las luchas de liberación en Centroamérica, como es el caso de los trabajos de Ignacio Martín Baró. Por ello, no es extraño que al develar su postura frente a lo público, estos jóvenes expresen un franco rechazo a las concepciones y prácticas de la política oficial. En los grupos de discusión se indagó su postura frente a las nociones de país, ciudadanía y política. Ahí, en el debate entre ellos, se manifestó un desplazamiento que partió de la oposición unánime al nacionalismo, para formular después su decepción en torno al país y el interés por la prioridad de la justicia por sobre una idea territorial de nación, para terminar reconociendo una pertenencia más regional, y finalmente, más planetaria.

"Yo era nacionalista, ahora creo que cada vez soy menos, cada vez tiene menos importancia en mi vida." (Participante, Grupo de discusión 1).

"A mi país yo lo quiero y no podría explicar por qué, mi país me gusta, sin embargo me está decepcionando muchísimo.” (Participante, Grupo de discusión 1).

Ser ciudadano es ser un sujeto activo, pero nada que ver con el Estado, porque no creo en él. (Participante, Grupo de discusión 1). "Me siento más latinoamericano" (Participante, Grupo de discusión 1). 
"Para mí la justicia es un motor que me mueve mucho, pues tienes que volverte un poco ciudadano del mundo aunque suene como a cliché, pero si ese es el tipo de cosas que te mueven a trabajar, ya no sólo por México sino por la gente que está igual en todas partes" (Participante, Grupo de discusión 1).

Todos los informantes argumentaron los motivos que sostienen su franca aversión por las prácticas de llamada clase política nacional.

"Así tal cual, la palabra política da asco a cualquier persona" (Participante, Grupo de discusión 2).

Pese a la variedad de formas de manifestar su aversión por la política oficial, los entrevistados, distinguen dos acepciones de la noción de política para deslindarse de una e inscribirse en la otra. Desdeñan la política estatal, en particular, la de los partidos políticos y se asumen como parte de la otra política, la que abre demandas, desde otros lugares para plantear a la estatal, vías alternas de incidencia.

"Si hacemos esto es porque no me gustan los espacios de participación que me ha ofrecido el Estado" (Participante, Grupo de discusión 2).

"Yo pienso que desde la trinchera de la sociedad civil es que se buscan otros medios para expresar que no estamos del todo de acuerdo y justo nosotros tomamos esta opción, yo personalmente, porque es como la más viable de generar un cambio en el sistema político. Creo que nuestras acciones sí son políticas. La campaña de alfabetización es política, Tlalana es política. Justo porque haces política desde la ciudadanía y eso es por lo que apostamos" (Participante, Grupo de discusión 2).

"Hemos optado por otras vías, no las gubernamentales. Hay muchas otras que no se han reconocido como formas alternas de participación ciudadana, muchos esfuerzos de comunidades urbanas y rurales, pero hay de trincheras a trincheras, no es lo mismo la política por presión que la política por construcción" (Participante, Grupo de discusión 2). 


\section{Conclusiones}

Las dos experiencias formativas que aquí se destacan abrieron para estos jóvenes la oportunidad de ser parte de la construcción colectiva de un orden de convivencia. En las escuelas a las que asistieron contaron con un lugar que incluyó su diferencia y pudieron aprender a expresar la propia opinión y a respetar la de los otros; desarrollaron capacidades para el debate y la construcción de acuerdos gracias a su participación en las asambleas y al hecho de que la expresión regulada de la opinión de los estudiantes es parte central de las prácticas educativas de instituciones que se nutren de los principios de la pedagogía crítica.

La participación voluntaria de estos hombres y mujeres jóvenes en las campañas de alfabetización abre la reflexión alrededor del papel que puede jugar el hecho de brindar a las y a los estudiantes la oportunidad de tomar sus propias decisiones y hacerse cargo de sus consecuencias. Ser parte de un proyecto común para el beneficio de una comunidad es crucial para la educación de las y los ciudadanos, pero ser parte de ello de manera voluntaria y sin la supervisión directa, ni presencial de las y los maestros y de los padres, al parecer es aún más crucial como fuente de desarrollo intelectual y emocional; de autonomía y compromiso social.

Esta consideración remite a la necesidad de trabajar alrededor del peso y las potencialidades que puede brindar el aprendizaje entre pares ya que, como lo destaca Smith (2010), el ejercicio ciudadano en esta etapa de la vida tiene que ver con la posibilidad de realización de un proyecto vital integrado a una colectividad.

Cabe destacar también que es preciso reconocer que no todo depende exclusivamente de la escuela y que hace falta darle un lugar a otros ámbitos de formación y de transmisión para analizar la posibilidad de fortalecer la sinergia con el trabajo escolar.

Fue gracias a los relatos de vida de las y los jóvenes involucrados en promover procesos de participación y autogestivos en otros jóvenes, que fue posible subrayar el papel que juega la dimensión cultural y biográfica para acercarse a las formas en que estas y estos nuevos actores sociales operan como eslabones vivientes de cadenas de sentido (Debray, 1997, p. 28). 
Desde una perspectiva intergeneracional (Alvarado y Vommaro, 2010), ello da cuenta de que esta vía de acceso a comunidades de sentido no implica, ni repetición, ni continuidad pues, como bien señala Potel (2010, p. 259), lo que se disemina siempre será distinto a lo heredado. La repetición al no poder nunca repetirse está condenada a producir lo nuevo, es decir, el acontecimiento, el otro.

Es así que, aunque esta nueva generación de actores sociales, da acuse de recibo, al compartir con sus predecesores una parte de sus aspiraciones, de sus estilos de trabajo y de intervención, testimonian los signos de su tiempo y en su búsqueda inauguran nuevas formas de entenderse a sí mismos y de actuar.

\section{Referencias bibliográficas}

Acevedo, A. y López, P. (2012) Ciudadanos Inesperados: Espacios de formación de la ciudadanía ayer y hoy. México. México: El Colegio de México y Centro de Investigación de Estudios Avanzados.

Aceves, J. (1988). Historia oral. México: Instituto Mora.

ADECO. (2011). Acciones para el Desarrollo Comunitario A. C. Recuperado de http://dig.do/adeco.org.mx

Alvarado, S. y Vommaro, P. (2010). Jóvenes, cultura y política en América Latina: Algunos trayectos de sus relaciones, experiencias y lecturas 1960-2000. Argentina: ClACSO Homo Sapiens.

Anzaldúa, R. (2006). Jóvenes frente al abismo. Revista Tramas, 24,105-134.

Bourdieu, P. (1998). La distinción. Criterio y bases sociales del gusto. Bogotá: Santillana.

Brezinka, W. (1999). Educación moral en una sociedad pluralista: condiciones culturales de éxito y sus límites. Revista Mexicana de Pedagogía, 48,11-16.

Bruner, J. (1995). Actos de significado. Madrid: Alianza.

Castoriadis, C. (1989) La institución imaginaria de la sociedad. Tusquets: Barcelona.

Castro, M. y Rodríguez, A. (2012). Pensar la Educación ciudadana en el México de hoy. Perfiles Educativos, 35, Número Especial, 129-141.

Cortina, A. (1997). Ciudadanos del Mundo. Madrid: Alianza.

Debray, R. (1997). Transmitir. Argentina: Manantial. 
Dubar, C. (2002). La crisis de las identidades: La interpretación de una mutación. Barcelona: Bellaterra.

Fernández, A. (2010). Formación ciudadana e identidad. México: Universidad Pedagógica Nacional.

Freinet. C. (1976). Técnicas Freinet de la Escuela Moderna. México: Ed. Siglo XXI.

Horacio, P. (2010). Cuestiones de herencia. Fantasma, duelo y melancolía en Jacques Derrida. En Casas, A., Constante, A. y Flores F. Los (con)fines del arte. Reflexiones desde el cine, el psicoanálisis y la filosofía. México: Universidad Nacional Autónoma de México.

House, E. y Howe, K. R. (1999). Values in education and social research. California: Sage Publications.

Instituto Escuela. (2011). Recuperado de http://institutoescuela.edu. $\mathrm{mx} / \mathrm{prepa}$.htm

Kymlicka, W. y Wayne N. (2003). Citizenship in Diverse Societies. USA: Oxford University Press.

Lechner, N. (1998). Nuestros Miedos. Perfiles, 13, 179-198

Mafessolli, M. (1990) El tiempo de las tribus. Barcelona: Icaria

Mason, T. y Delandshere, G. (2010) Ciudadanos, no sujetos de investigación: Hacia una metodología de investigación en educación cívica más democrática. Revista Interamericana de Educación para la Democracia, 3 (1) 1-24. Recuperado de https://scholarworks.iu.edu/journals/index.php/ried/article/.../1065

Melucci, A. (2002). Acción colectiva, vida cotidiana y democracia. México: El Colegio de México.

Nagel, T. (2004). La posibilidad del altruismo. México: Fondo de Cultura Económica.

Palmas, S. (2012). Hoy, aquí, alfabetizando. Treinta años de alfabetizar por convicción,

Revista Decisio, 33, 41-46.

Pettit, P. (1999) Republicanismo. Una teoría sobre la libertad y el gobierno. Barcelona: Paidós.

Reguillo, R. (2004). La Performatividad en las Culturas Juveniles. Revista Estudios de Juventud, 64, 49-56.

Torres, R. (2001) Participación ciudadana y Educación. Una mirada amplia y 20 experiencias en América Latina. Documento para la Segunda Reunión de Ministros de Educación del Consejo 
Interamericano para el Desarrollo Integral-CIDI. Recuperado de http://portalsej.jalisco.gob.mx/consejo-estatal-participacion-social/sites/portalsej.jalisco.gob.mx.consejo-estatal-participacion-social/files/pdf/participacionciudadana.pdf

Turner, V. (1988) El proceso ritual. Madrid: Taurus.

Yuren, M. (2011) Educar en el presente para la eticidad del futuro. En Espinosa, J. Educación y Eticidad. Reflexiones en las distancias. Homenaje a Teresa Yuren Camarena. (pp. 13-34) México: Juan Pablos Editor. 